\title{
Research on the Relationship between Building Industrialization and Labor Productivity of China
}

\author{
Tang, M.H. ${ }^{1, a}$, Ren, H. $^{1, b}$ and, Huo, T.F. ${ }^{1, c}$ \\ ${ }^{1}$ School of Construction Management and Real Estate, Chongqing University, China \\ ateie@foxmail.com, ${ }^{\mathrm{b}} \underline{1341751509 @ q q . c o m},{ }^{\mathrm{c}}$ htf2010@sina.cn
}

Keywords: Construction industry; Labor productivity; Cobb-Douglas production function; Building industrialization

\begin{abstract}
This paper analyzes the relationship between building industrialization and labor productivity. Based on Cobb-Douglas production function, the labor productivity model is established to evaluate the effect degree of building industrialization of labor productivity, then a case study of China's construction industry from 2000 to 2014 is used to evaluate the effect degree. The results demonstrates that the effect of building industrialization on the labor productivity is greater than capital investment, with the percentage of building industrialization increasing by $57.28 \%$, and the percentage of capital investment increasing by $42.72 \%$. Overall the results indicated that building industrialization is an effective way to improve labor productivity in the construction industry.
\end{abstract}

\section{Introduction}

In recent years, construction industry of China has developed rapidly and become the leader of Chinese economic development. Meanwhile, the share of construction added value in GDP also increased from $5.58 \%$ in 2005 to $6.86 \%$ in 2015 [1], the proportion is much higher than other industries. However, the mechanization level of construction industry in China is low. At present the on-site manual production mode is widely used in construction industry production, and production processes are still dominated by manual operation, which directly lead to the low labor productivity of construction industry of China. According to the study report from US Institute of Construction shows that labor waste and ineffective work is up to $57 \%$ in the construction production process[2], labor productivity is less than one-half of the manufacturing industry[3]. The industrialization of construction industry is proportional to the labor saving, and the higher the proportion of industrialization, the more labor saving and the lower the demand for the labor force in the construction industry. Therefore, building industrialization plays an important role in saving labor force, it can improve the efficiency of labor production greatly and ensure the rapid development of the construction industry.

\section{Method}

The Cobb-Douglas production function assumes that the proportion of inputs in the total ratio of the same, labor and marginal substitution rate of the cost unchanged [4,5], the expression is as follow

$$
Y=A K^{\alpha} L^{1-\alpha}
$$

Where $\mathrm{Y}$ is output, $\mathrm{K}$ is capital investment, $\mathrm{L}$ is labor force; $\alpha$ is output elastic coefficients of capita; $\mathrm{A}$ is a constant. It is necessary to take time as a variable when consider the relationship between output, labor force and capital investment at one moment. And the Solow's growth equation is calculated by

$$
Y_{\mathrm{t}}=A_{t} K_{t}^{\alpha} L_{t}^{1-\alpha}
$$


Let the left and the right side of the equation divided by labor input at $t$ time, which is determined by the following formula:

$$
\frac{Y_{\mathrm{t}}}{L_{\mathrm{t}}}=A_{t}\left(\frac{K_{t}}{L_{\mathrm{t}}}\right)^{\alpha}
$$

$\frac{Y_{\mathrm{t}}}{L_{\mathrm{t}}}$ is the labor productivity of construction industry at t time, which is calculated by

$$
\mathrm{r}=m+\alpha q
$$

The growth rate of capital equipment ratio $(\alpha q)$ and the growth rate of construction industrialization

$(\mathrm{m})$ determine construction labor productivity $(\mathrm{r})$ and they show a linear correlation. Furthermore, $\mathrm{E}_{1}$ is the degree of promotion of the efficiency of building industrialization for labor productivity of construction industry; $\mathrm{E}_{2}$ is the degree of promotion of capital investment for labor productivity, which is calculated by

$$
\begin{aligned}
& E_{1}=\frac{\mathrm{m}}{r} \times 100 \% \\
& E_{2}=\frac{\alpha q}{r} \times 100 \%
\end{aligned}
$$

\section{Measuring process}

This paper chooses the number of staff and workers in construction, the value-added of construction and the net value of fixed assets as the sample from 2000 to 2014, which are from the China Statistical Yearbook (2000 -2015). In order to eliminate the impact of inflation, the nominal GDP is converted into the real GDP for all years respectively, based on the price of 2000. As shown in Table 1.

Table 1 Main Indicators of Construction Industry of China from 2005 to 2014

\begin{tabular}{|c|c|c|c|}
\hline Year & $\begin{array}{l}\text { Number of staff and workers in } \\
\text { construction (million people) }\end{array}$ & $\begin{array}{c}\text { Value-added of construction } \\
\text { (billion yuan) }\end{array}$ & $\begin{array}{c}\text { Net value of fixed } \\
\text { assets (billion } \\
\text { yuan) }\end{array}$ \\
\hline 2000 & 2097.45 & 3341.09 & 2831.25 \\
\hline 2001 & 2283.40 & 4023.57 & 3571.63 \\
\hline 2002 & 2432.34 & 3822.42 & 4318.76 \\
\hline 2003 & 2663.49 & 4654.71 & 4547.58 \\
\hline 2004 & 2688.63 & 5615.75 & 4928.40 \\
\hline 2005 & 2945.20 & 6899.71 & 5056.50 \\
\hline 2006 & 3153.10 & 8116.39 & 5520.02 \\
\hline 2007 & 3446.68 & 9944.35 & 5990.69 \\
\hline 2008 & 3849.50 & 12488.95 & 6654.69 \\
\hline 2009 & 4149.90 & 15619.82 & 7591.92 \\
\hline 2010 & 4708.34 & 18983.54 & 8299.91 \\
\hline 2011 & 5021.72 & 22070.98 & 8889.91 \\
\hline 2012 & 4629.06 & 26583.31 & 9582.58 \\
\hline 2013 & 5271.45 & 33071.51 & 9910.36 \\
\hline 2014 & 5563.47 & 35270.15 & 10630.41 \\
\hline
\end{tabular}

* The economic indicators are calculated at comparable prices. 
Based on dates (Table 1), the annual labor productivity, capital equipment rate and its change value can be calculated. For the determination of $\mathrm{m}$ and $\alpha$ parameters can be used to experience value method, point estimate method andleast square method [6]. The experience value method is used to estimate the $\mathrm{m}$ and $\alpha$ parameters from the past experience, but due to the uncertainty and complexity of economic problems, the estimated parameter values of this method tend to be larger; the point estimate method is based on the study of the two points of the study interval, but the method does not take into account the change of the economic indicators between the two points, so the parameter value obtained is not the optimal value[7]; the least square method takes into account the whole time interval when estimating the interval of the parameters, which can make up for the shortcomings of the experience value method and the point estimate method. Therefore, the following will be used to the least square method, which is calculated by

$$
\begin{gathered}
\alpha=\frac{\mathrm{n} \sum r q-\sum r q \sum q}{n \sum q^{2}-\left(\sum q\right)^{2}} \\
m=\frac{\sum r}{n}-\alpha \frac{\sum q}{n}
\end{gathered}
$$

Table 2 Analysis on the Factors of Labor Productivity Growth in construction industry of China

\begin{tabular}{|c|c|c|}
\hline Factors & Average annual growth rate (\%) & Effect degree (\%) \\
\hline $\begin{array}{c}\text { The average growth rate } \\
\text { of labor productivity }\end{array}$ & 18.37 & 100 \\
\hline $\begin{array}{c}\text { Construction } \\
\text { industrialization }\end{array}$ & 10.52 & 57.28 \\
\hline Capital equipment & 7.85 & 42.72 \\
\hline
\end{tabular}

As shown in Table 2, the labor productivity of the construction industry has been booming year after year, and annual average increase rate of labor productivity is $18.73 \%$ from 2000 to 2015 . And labor productivity increase from 15900 per person to 63400 yuan per person from 2000 to 2014, which increase four times. But compared with the industrialized countries, the labor productivity of construction industry of China is low, according to the statistics, labor productivity of China is only one-twelfth of the United States and one-eleventh of Japan. The reason is that the construction mechanization is relatively low, and there is needed a lot of manual work during production. The efficiency of traditional manual operation is easily affected by technical proficiency, professional skill and enthusiasm of workers, so the traditional manual operation is considered less efficient than construction industrialization.

\section{Conclusions}

In this paper, we use decomposes the labor productivity in construction industry into building industrialization and capital investment using Cobb-Douglas production function, then an empirical study is done to measure the impact of these factors on labor productivity. It shows that the output elastic coefficients of labor enhanced more than capital, which indicates that construction groups always lie on a huge supply of cheap labor in construction industry instead of technological innovation. And it also shows that the effect degree of building industrialization on labor productivity is $57.28 \%$, the capital equipment is $47.28 \%$, and the effect of building industrialization on the labor productivity of construction industry is greater than capital investment, which can highly improve the labor productivity of construction industry. Improving building industrialization level is an effective 
way to enhance the labor productivity of the construction industry in China, but as a new production method, there are too many obstacles in the process of implementation. Therefore, Chinese government needs to develop policies to speed up construction industrialization, especially in standard production and mass production which can reduce costs of construction enterprises. The reduction of production cost is a critical factor for construction enterprises, and more companies may adopt construction industrialization, then building industrialization can gradually take the place of traditional manual operation, finally labor productivity of construction industry can be improved effectively.

\section{Acknowledgements}

This work was financially supported by the Shanghai Natural Science Foundation (0666666), Innovation Program of Shanghai Municipal Education Commission (060000) and Shanghai Leading Academic Discipline Project of Shanghai Municipal Education Commission (0555555).

\section{References}

[1] Halfawy M M R, Froese T M. Component-Based Framework for Implementing Integrated Architectural/Engineering/Construction Project Systems[J]. Journal of Computing in Civil Engineering. 2007, 21(6): 441-452.

[2] D S. Rethinking Construction[J]. Health Estate. 1998, 20(volume 10(1)): 83-102.

[3] Steven G A. Why Construction Industry Productivity is Declining[J]. 《Review of Economics \& Statistics》. 1989, 71(3): 661-669.

[4] Proverbs D G. Productivity rates and construction methods for high rise concrete construction: a comparative evaluation of UK, German and French contractors[J]. Construction Management \& Economics. 1999, 17(1): 45-52.

[5] Fayek A R, Oduba A. Predicting Industrial Construction Labor Productivity Using Fuzzy Expert Systems[J]. Journal of Construction Engineering \& Management. 2005, 131(131): 938-941.

[6] Mohamed S, Srinavin K. Forecasting labor productivity changes in construction using the PMV index[J]. International Journal of Industrial Ergonomics. 2005, 35(4): 345-351.

[7] Wenxian W, Qiming L, Xianguang L, et al. A Comparative Study of International Construction Industry Productivity[J]. Journal of Chongqing Jianzhu University. 2007(06): 136-140. 